\title{
Lost at sea: The Freudian uncanny and representing ecological degradation
}

\author{
Janne Seppänen \\ Department of Journalism and Mass Communication, University of Tampere, \\ Tampere 33014, Finland. \\ E-mail: janne.seppanen@uta.fi
}

Abstract This article focuses on an unusual press photograph depicting the
worsening ecological crises in the Gulf of Finland. The emotional register of the picture
could be described as uncanny, a psychoanalytical term that serves as the main
theoretical concept of the paper. Two questions are discussed: How does the
photograph work in the light of psychic functions connected with the uncanny
experience? What are the political implications of these functions in the context of the
photograph? The theoretical bias focuses on some of the psychic dimensions of the
uncanny: denial and repression. The discussion, however, departs from its Freudian
base by emphasizing the social and political disposition of the unconscious. The paper
elucidates how the photograph oscillates between reality and imagination, beauty and
dirtiness, familiarity and unfamiliarity. The social significance of the uncanny as a
representational strategy appears to be uneven and paradoxical. On one hand, it may
provide a means to question the basic tenets of the social reality and, hence, the status
quo. On the other hand, the uncanny may provoke the denial of the very same reality
and obscure its changeability.
Psychoanalysis, Culture \& Society (2011) 16, 196-208. doi:10.1057/pcs.2010.32

Keywords: uncanny; psychoanalysis; climate change; photography studies; visual culture

In 2007, the winner of the Finnish Press Photos of the Year Competition was photographer Hannes Heikura. He won in the two most prominent categories, Picture of the Year and Press Photographer of the Year. The winning photograph (Figure 1) in the first category depicts a sailboat cruising in the middle of the Gulf of Finland, where extreme flowering of algae is leading to a worsening ecological crisis. The picture was published in the biggest Nordic daily, Helsingin Sanomat (2007) and can be seen in colour on the Finnish Press Photographer's website (http://www.suomenlehtikuvaajat.fi/ 


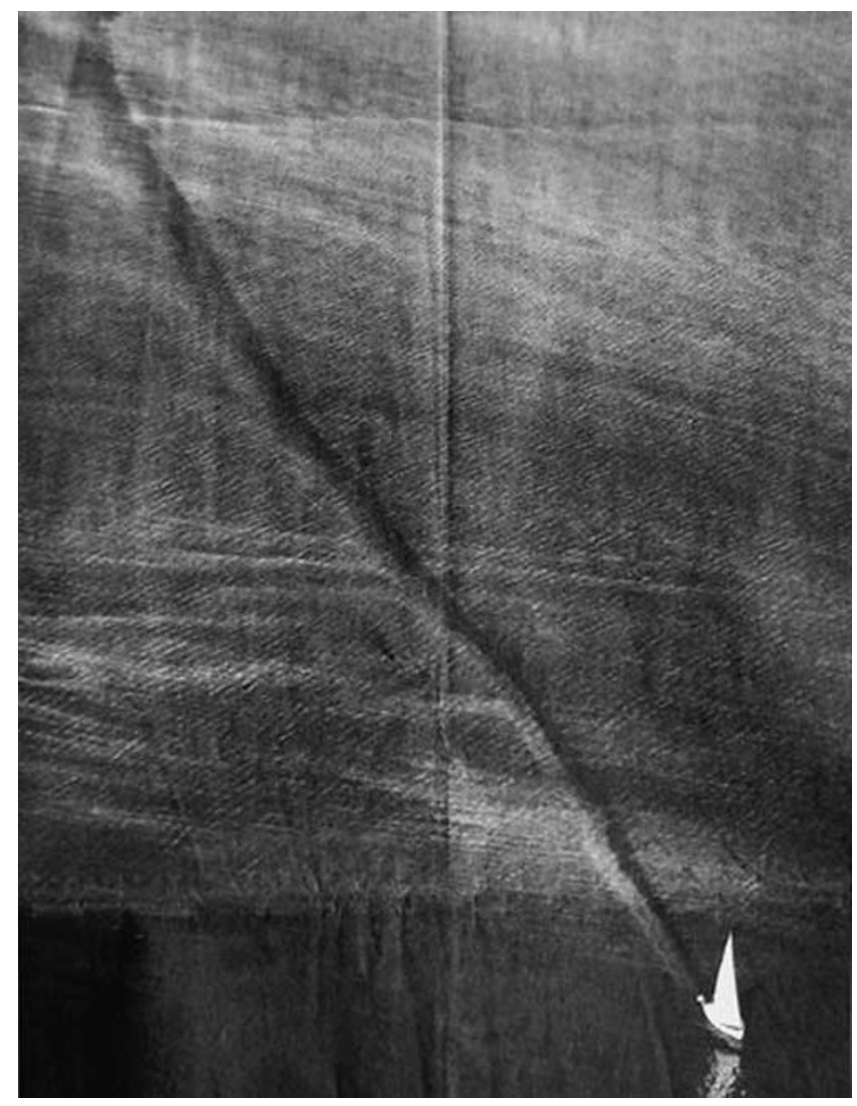

Figure 1: "Lost at Sea." Photograph by Hannes Heikura. Reproduced by permission of Helsingin Sanomat.

vuodenlehtikuvat2008/2007/). The jury of the competition characterized the photograph as follows:

Frightening and beautiful, these were the terms the jury used to describe the winning picture. Occasionally, the discussion was heated: do readers understand the meaning of the picture? ... The picture directs the viewer's attention to a very important phenomenon, which is also hard to capture in a photographic image, namely climate change. We chose the picture because it was at the same time frightening and beautiful. It is also a picture of a very up-to-date topic.

To the jury, the photograph is a depiction of climate change. First and foremost, however, it represents the consequences of the eutrophication of the Baltic Sea, where a substantial nutrient load - mainly phosphates and nitrates - produces extreme algae growth. As a consequence, the surface of the sea turns into a thick, sometimes that after poisonous mass is largely caused by wastewater 
discharge and agricultural fertilizers. When algae decomposes, it uses the available oxygen, changes the biological equilibrium of the sea and causes deaths of fish and other organisms. Global warming amplifies the process, because warm surface water increases algae growth.

I am interested in the atmosphere of the image, which is characterized by the jury as 'frightening and beautiful'. I share these impressions but would add one more: the atmosphere is uncanny. The thesaurus on my computer suggests several synonyms for the term, including weird, strange, and mysterious, all of which resonate with the sentiments and emotions I experience as I view the photograph.

The uncanny is a concept that has been discussed extensively in different branches of inquiry: philosophy, literary and art criticism, and political theory. Karl Marx, Friedrich Nietzsche, and Martin Heidegger, among others, have all elaborated the idea in different contexts (Royle, 2003, pp. 1-38). The most significant figure, however, is Sigmund Freud (1919), who laid the cornerstone for many subsequent discussions (see, eg, Hoile, 1984; Heischman, 2002; Carrington, 2005; Israeli, 2005; Baumont, 2006).

It is well established that psychoanalytic theories play a crucial role in the field of visual culture studies. This was already the case in the film theory of the 1960s or, even earlier, in Jacques Lacan's or Jean-Paul Sartre's formulations of the gaze and looking. In film studies, psychoanalytical thinking merged with semiotics, a 'psycho-semiotic' paradigm that gained a somewhat hegemonic position by the end of the 1980s and also gave rise to notable criticism, for example, by David Bordwell and Noël Carroll (1996). Photography studies also employed psychoanalysis from the mid-1970s onwards (eg, Burgin et al, 1986; Burgin, 1987, 1996). However, the thematic of the uncanny has very rarely been used in analyzing photographic images (see Frosh, 2001; Salvio, 2009).

Leaving all those debates aside, I draw now from Freud's (1919) conception of the uncanny. Returning to Freud does not mean that I accept his thinking in toto, nor inevitably his theoretical cornerstones, including the oedipal triangle, castration anxiety, or traditional, family-bound object relations. I do believe, though, that certain more or less unconscious mental functions - like denial ${ }^{1}$ and repression - are factual in the sense that they are part of our daily lives and hence produce and mediate our relationship to society and culture at large. Hence, in my reading, Freud becomes slightly deterritorialized, and I use his concepts to understand how photography, like familial relations, works in a complex and obscure zone between psyche and culture without reducing those functions to any master narrative. I use psychoanalytical concepts to show how certain representation works, not what it ultimately means (Deleuze and Guattari, 1983). My approach also leaves aside the question of situating the essay in Freud's thought in general, as well as the substantial discussion of the problems of its inner logic (Weber, 1973), and engages the concept of the uncanny in a more superficial but, I hope, also a more accessible way. 
The primary context of the image is, of course, the newspaper article. The image, text, graphic design and layout together create a unique narrative where it is difficult to capture the signifying moment of one individual element. Another obvious milieu for the image is the exhibitions and the book, where it is accompanied by a short caption. These several contexts have different audiences, too. Hence, the analysis of the photograph alone does not automatically take into consideration its many meanings in the context of narrative and layout, let alone its interpretations by different audiences. Thus, my endeavour shares all the risks following from a theoretical reading that leaves aside the production process and the reception (see Bordwell and Carroll, 1996).

This article discusses two interrelated questions. First, how does the photograph work in light of the psychic functions connected to uncanny experience? Second, what are the political implications that these functions might occasion in the context of Heikura's photograph? In the following sections I dismantle the concept of uncanny into its elements and track the psychic dynamics revolving around it. Finally, by pondering its political implications, I consider the uncanny as a critical strategy.

\section{A Theory: The Uncanny}

For Freud (1919) uncanny meant something strange that is 'frightening' and 'arouses dread and horror', but it also connotes something 'familiar' (p. 219). The faintly paradoxical emotional tenor of the uncanny is also recognizable in many Hollywood films. In Stanley Kubrick's film The Shining (Hoile, 1984), the male protagonist step-by-step turns into a monster, obsessed with delusions and paranoiac thoughts. A familiar and caring figure, a father, grows into a maniac trying to massacre his family. What is typical of the filmic uncanny in many cases is its slow emergence: the madness gradually gives more and more hints as the narration proceeds.

A sensation of the uncanny also arises when one feels that the line between reality and imagination is about to blur. Is this something that really is happening, or is it only in my imagination? Everybody can identify similar feelings as a part of everyday experience; if the uncanny sensations are strong enough, however, the connection to reality may become fatally disturbed. Other fictive narratives as well as movies also exploit this sensation, but the line between reality and imagination can be threatened by real events, too. The most obvious examples are the online pictures of the 9/11 terrorist attacks. For many viewers seated in front of their TV sets the first impression was, is this a real event or footage from a Hollywood catastrophe movie? The unreality of the reality itself undermined the basic realistic mode of the online TV broadcast: the impossible had happened. 
A similar tension between reality and imagination is also present in Heikura's photograph. The image itself has clearly surrealistic overtones, generated by unnatural colours. These move the signification far beyond the straight realism of the everyday press photograph. At the same time, the generic quality of the image as a press photograph does not disappear. To a degree, the uncanny effect is an outcome of the form of expression, which violates the generic codes of the photographic image as a documentary reflection of basic reality. Nonetheless, it could be argued that the colour saturation of Heikura's picture depicts reality in front of the camera. The sea looks as it looks in reality. There is nothing surreal or unnatural about it. The point is that the image does not punch our conception of reality as such; rather, it strikes against the conception of reality constituted through the generic expectations of press photography.

The relation between the real and the imagined inhabits the picture at another level, too. The most urgent debate concerning the relation to nature is about the 'realness' of climate change. Regardless of ample evidence, doubts are still raised about its existence. The debate resonates with the most tangible uncanny feelings connected to abnormal climate occurrences. In Finland, for example, the winter of 2008 was extraordinarily warm and virtually snow free in the southern parts of the country. People kept saying that there was something 'strange' or 'wrong' with the climate. Contemporary discourses and experiences revolving around the climate promote a cultural condition that shifts the borders between natural and unnatural, real and imagined events. From this point of view, the jury's contextualization of the picture becomes reasonable: the primary content of Heikura's photograph is not local eutrophication but global climate change.

In the picture, the uncanny feeling is also connected to the disruption of the harmony of nature. The familiar and harmonious impression of the Finnish archipelago has disappeared, and something strange, anomalous, has emerged instead. In the history of philosophy and natural sciences the concept of harmonious nature dates back to antiquity, is powerfully present in the birth of the modern natural sciences, and lives on in physics and chemistry. For instance, scholars have been particularly interested in the different kinds of symmetries of elementary particles (Meinzer, 1996). The idea of living in harmony with nature and the concept of ecological balance are also used both in everyday discussion and in scholarly debates. Depictions of perfect sunsets, clean waters, and a blue sky with clouds hardly contain any disharmonious elements. Forms of nature have affected the composition principles of art and design, the golden section and its assumed harmonizing effects being the most obvious example.

Heikura's photograph challenges harmony in a peculiar manner. As the jury states, the picture is both frightening and beautiful. In my reading, the frightening elements stem from the picture's depiction of a serious environmental problem. Impressions of beauty derive from the composition of the image, which is harmonious indeed. The form (composition) recalls the 
imaginary harmony of nature, while the content (environmental catastrophe) gives an entirely different impression with explicitly disharmonious overtones. Paradox is a fundamental attribute of the photograph and also a source of uncanny feelings.

Freud himself was not particularly preoccupied with the questions of aesthetic harmony and visual representations. He wrote only two texts focusing attention on the visual: the first considered Leonardo da Vinci (1910); the second, Michelangelo's famous statue of Moses (1914). Both texts provoked extensive debate and criticism, which have to be omitted here (but see Fuller, 1983). In post-Freudian psychoanalytic thinking, however, the theme of harmony in the arts and its connection to inner psychic processes can be found. Hanna Segal outlines the relationship between the ugly and the beautiful:

From the psychoanalytic point of view ... the ugly corresponds to the destroyed, to what is fragmented, lacking in rhythm and wholeness and harmony. I would say the ugly signifies the destruction of the internal world and its results; the beautiful is usually seen as the rhythmical, the harmonious, the whole - corresponding to the experience of loved, whole, good object and self. Both the ugly and the beautiful are an essential part of aesthetic experience. A work of art devoid of the elements we might call ugly would not be beautiful, but merely pretty. (cited in Fuller, 1983, p. 118)

Segal's thinking draws on the Kleinian framework, which, of course, differs from Freud's. But the idea that the ugly corresponds to a destroyed and fragmented internal world and the beautiful to a harmonious, whole self sounds plausible. Segal's idea that to be beautiful artwork should contain some ugly (disharmonious) elements, too, is interesting in the context of Heikura's photograph. The harmonious beauty of the photograph would, indeed, be nothing without ugly, disharmonious elements. This is, as I stated earlier, one reason for the uncanniness of the picture.

The tension between reality and imagination, harmonious and disharmonious, and ugly and beautiful may well accompany another dichotomy, namely, clean versus unclean. It could be argued that the factual content of the picture literally pollutes an otherwise harmonious image and renders it unclean. Mary Douglas (1988) speaks about pollution as a ritual exposing the orders of social or religious life, the sacred and the secular. Concrete dirt is a relative matter and sometimes forms rather complicated networks of significations. She writes: 'Reflection on dirt involves reflection on the relation of order to disorder, being to nonbeing, form to formlessness, life to death' (p. 5).

The viewer of the image is taken close to this disorder, but in a subtle manner. The photograph does not reveal its content explicitly: we are not witnessing a ruthless representation of dying animals or raped forests. On the contrary, the 
image itself is more like an abstract painting - a silent, flat surface. This nonfigurative quality is one reason the members of the jury became concerned about the spectators' 'understanding' of the image. To put it bluntly, the jury was afraid that the aesthetic qualities of the photograph would suppress the frightening content. This notion recalls the disputes about the aestheticization of serious social issues, such as violence or poverty, in the field of documentary photography. The basic line such criticism stresses is that the aestheticization of poverty undermines the social and cultural conditions behind deprivation and also elevates the photographed subjects to suffering heroes and the photographers to great artists (see, eg, Solomon-Godeau, 1993).

In Heikura's case the aestheticization may help to promote artistic endeavours, but it also creates, for its part, an uncanny feeling, which underlines the disgusting features of the algae growth. The representational strategy poses serious questions concerning the relations between aesthetics and politics, which I address in the conclusion to this article.

\section{Repression and Denial}

All the aforementioned features of the uncanny are relatively easy to recognize. To understand the uncanny more thoroughly, however, we need to dig deeper into its psychic dynamics. Freud (1919) discussed at length the meanings of the German word for uncanny, unheimlich. He cited Schelling, who stated that 'everything is unheimlich that ought to have remained secret and hidden but has come to light' (p. 222). This 'secret' but 'familiar' nature of the uncanny led Freud close to the problem of repression, and he actually stated that the uncanny is something 'repressed which recurs' (p. 241). Consequently, the uncanny is nothing new, but something familiar that has become unfamiliar. It is 'something which is familiar and old-established in the mind and which has become alienated from it only through the process of repression' (p. 241). Later, Freud asserted that repression may work as a process behind the feeling of the uncanny, but not everything that is secretly familiar and returned from repression is felt as uncanny.

In the context of the uncanny Freud did not elaborate the concept of repression in detail. However, in a famous paper written four years earlier he explicitly approaches the topic and binds it to the satisfaction of instinctual needs and neurotic symptoms. Freud (1915) summarized: 'The essence of repression lies simply in turning something away and keeping it at a distance, from the conscious' (p. 147). For him, the main motive for repression is avoidance of discomfort. By repression the ego protects itself against thoughts, images and memories that may cause distress and threaten its stability. For Freud, repression operates as a prototype for other defence mechanisms, and, in the context of this article, the most fascinating of these is denial. 
Denial and repression are essential psychic functions not only in mental disturbances but also in normal mental life. We all repress innate feelings and deny demands and stimuli coming from external reality. The metaphor 'to close one's eyes' tells much: if the viewed scene is too distressing or traumatic, we do not want to look at or know anything about it. That denial is utilized by the advertising industry. For example, numerous car advertisements connect climate change with buying a new vehicle. The car and nature are frequently depicted in a harmonious manner: a car with low $\mathrm{CO}_{2}$ emissions is sometimes even presented as being part of nature. Advertisements present a fantasy that consumption can actually solve problems. From this point of view, one could easily argue that some advertisements advocate a state of mind that denies basic reality and builds up a more pleasurable phantasmatic reality of their own. That is, advertisements exploit reality by providing an imaginary solution to the distressing problem to help us to repress our basic fears by the denial of reality. The strategy is a classic one: advertisements promise a symbolic solution to problems by inviting people to consume not less, but in the right way.

Heikura's picture is of another genre (press photography) but relates itself inevitably to these other imaginaries of nature. It seems that Heikura's picture provides no opportunity for denial by constructing an alternative, fictive reality. On the contrary: it hits straight at the viewer's fears by depicting the worsening ecological crisis in a beautiful manner. This tension is one reason why the photograph does not provide any imaginary solution or relieving closure, as do many representations of nature from automobile ads to nature films. It plainly depicts a white sailboat in the middle of algae growth. One could argue, though, that the viewer does not want to know anything about the worsening situation in the Gulf of Finland. Maybe she or he will turn the page and try to deny the distressing image (and the whole article) altogether. Another source of denial may be in the upsetting figure of the dirty/polluted/overgrown object, which transgresses all the limits of normal growth. This filth is something that should be kept at a distance because it threatens to pollute not only the sea but, in a sense, the viewer as well, because feelings of dirt, degradation, and suffocation can be sensed in a very bodily manner.

There may be a fragment of truth in these interpretations, but certain elements in the photograph speak against them, for example, its appealing beauty and harmony. Owing to its harmonious composition, the photograph could work against repression and give denial a chance to fail: it entices the viewer to look at the picture, which is not straightforward but, rather, slightly enigmatic. Although a viewer could be provided with contextual information, she or he does not necessarily understand the picture at first sight. The photograph requires a long look. The harmonious composition of the image addresses the viewer's ability to enjoy a pleasurable representation without instantly succumbing to distressing sentiments. In addition, the enigmatic quality of the image provides pleasure in looking and hence entices one to cast 
an enduring look. This is a situation where the subject vacillates between two conflicting psychic forces. On the one hand, she or he is driven by the desire to look (I need to know/look/see), and, on the other, her or his ego is protected by repression and denial (I do not want to know/look/see). It seems that this conflict works as one source for the uncanniness of the picture.

For Freud (1919), the feeling of the uncanny is tied to very deep layers of the human psyche, including unconscious fears and related emotions. It dates back to the phases when 'ego has not yet marked itself sharply from the external world and from other people' (p. 236). This is something that is true in the case of the return of the repressed, too, which, as I have mentioned, is connected to the feeling of the uncanny. The algae growth and eutrophication in the Gulf of Finland are the most realistic but also the most superficial levels of the picture. In actuality, the picture is about a context of death and extinction. It is about the mortality of nature and of human beings as well. And if there is something 'repressed that recurs', it is these very feelings of mortality, extinction and chaos, which humans have to repress in everyday life.

\section{Conclusion: Lost at Sea}

Most of us are aware of climate change but, at the same time, are unwilling to change our actions or even think about the whole issue, which seems too frustrating, complicated and distressing to bear. Hence, denial is paradoxical: it is both knowing and not-knowing (Cohen, 2001). The paradox is a social fact to the core, and from its history one could pick up startling examples of its political consequences: In what sense were (if they were) ordinary Germans aware of the concentration camps? Did they wonder where all the Jews were being transported? Did they discuss the topic with their neighbours?

The cultural repercussions of denial and repression extend their influence from the ordinary flow of everyday life to the most terrible historical events. And, sometimes, these two coincide and render the unconscious politically loaded. This is something that Fredric Jameson (1981) also refers to as the 'political unconscious': the idea that the unconscious is not a flow of amorphous mental impulses but, rather, it is composed of socially shared and politically relevant functions. These functions mould the production and reception of 'symbolic acts' (representations) and narratives in society. Therefore, overcoming denial and repression opens up a possibility - but only a possibility - of facing up to and acknowledging socially and politically loaded environmental problems.

The central question here is, how does the uncanny work, if it indeed works, as a critical strategy in Heikura's photograph? To answer how a particular representation or symbolic act really works at the unconscious level is, of course, an extremely difficult task. 
Heikura's picture fulfils its documentary aim in a strange manner by addressing the viewer's imagination with surrealistic colours and rendering the signification far beyond that of everyday press photography. Another paradox oscillates between the aesthetic form and the degrading of nature. The uncanny feeling arises from the ambiguity between the beautiful composition of the picture and the dirty, polluted sea. The third tension spans the divide between the familiar and unfamiliar, where the harmonious and picturesque image of nature has suddenly been corrupted by the strange, suffocating, and alien mass. Using these strategies, Heikura challenges the familiar visual orders (see Seppänen, 2006) or imaginaries that characterize typical representations of nature and landscape. These orders - as expressed in romantic, unspoiled, and harmonious images - are deeply embedded in historical as well as contemporary discourses and representations of nature. They can be found in advertisements, coffee table books, and nature photography competitions. These images form the core of the fantasies that construct a part of our imaginary relation to nature, and they also serve as projections and as introjections of wishful thinking, in at least two forms.

First, they serve a nostalgic desire to flee from the present world, where different kinds of catastrophes always threaten nature and our relation to it. Second, purified representations maintain the desire that unspoiled nature still exists and will exist in the future, too. The visual order of intact nature upholds an imaginary relation to nature, which gives way to wishful thinking and fantasies and, at least partly, denies the reality. What is repressed are the fear of and the guilt from the extinction that results from ecological crisis; what is fantasized is its symbolic solution by consuming goods or through imaginary representations. Hence, real social problems find solutions in the symbolic acts in the aesthetic realm (Jameson, 1981, p. 79). This chain of significations is something that Heikura's picture works against, or, at least, does not support.

The viewer may find Heikura's photograph unpleasant and disturbing, which may evoke repression and denial. Because of its aesthetic qualities, however, the photograph may also invite the viewer to take a longer look, help to contemplate the obscure signification and assist the repression and denial to fail. The paradox of the uncanny is described by Samuel Weber (1973), who sees the uncanny as a 'certain indecidability which affects and infects representations, motifs, themes, and situations, which ... always mean something other than what they are and in a manner which draws their own being and substance into the vortex of signification' (p. 1132).

From that point of view, the uncanny as a critical strategy does not provide any stable political stance, but 'indecidability' is also accompanied by a desire to 'uncover the facade and discover what lurks behind' the picture, photograph, scene. And the 'desire to penetrate, discover and ultimately to conserve the integrity of perception: perceiver and perceived, the wholeness of the body, the power of vision ... all this implies a denial ... a denial that in turn involves a certain structure of narration, in which this denial repeats and articulates itself' (p. 1133). 
The desire to conserve the 'integrity of perception' expresses itself in the jury's statement (quoted at the beginning of this article), which takes the leading narrative of the photograph as global warming, not the original subject matter: eutrophication. It seems that, currently, global warming works as a sort of grand narrative, providing a context for many environmental problems regardless of their origin. By connecting the photograph to climate change, the jury tries to stabilize the meanings and get rid of the basic 'indecidability' of the picture. The jury's statement also radiates distress about the reader's ability to understand the 'meaning of the picture', even though it does not mention exactly what the meaning could be. Here the statement speaks of the desire for meaning in the face of the representation, which does not easily lend itself to clear-cut significations. The jury's wariness of the communicative function of the picture also demonstrates the unstable nature of its signification.

In summary, the uncanny provides an emotional register that helps us to question the everyday world by unfixing its status as a reality and making it unfamiliar. This representational quality connects the uncanny to the long history of different defamiliarizing strategies. Already in the late eighteenth century the German Romanticist poet Novalis stated that the poet should make the familiar strange and the strange familiar. At the beginning of the twentieth century the Russian formalist Victor Shklovsky wanted to differentiate ordinary language from artistic and poetic expression, the latter providing new ways of perceiving reality by defamiliarizing (ostranenie) things. The third example is, of course, Bertold Brecht, whose Verfremdungseffekt owes much to the legacy of Russian formalism (Davis and Womack, 2001, p. 41). One could argue that the ability to question the world by rendering it unfamiliar in order to see it more clearly is essential for any critical agency aimed at shaking up the status quo. At the same time, however, this uncanny 'indecidability' can also strengthen the prevailing social reality by mobilizing denial and the phantasmatic desire for the more pleasurable imagined realities. This is the Scylla and Charybdis of Heikura's unusual press photograph, too.

\section{About the Author}

Janne Seppänen is Professor of Visual Journalism at the University of Tampere, Finland. He is the author of The Power of the Gaze: An Introduction to Visual Literacy.

\section{Note}

1 There has been much debate about the correct translation of Verleugnung (denial or disavowal) as well as Freud's somewhat inconsistent use of the concept (Cohen, 2001, pp. 25-28). In this article I use the term denial, except in direct quotes from established translations of Freud's texts. 


\section{References}

Baumont, M. (2006) Red Sphinx: Mechanics of the uncanny in the time machine. Science Fiction Studies 33(2): 230-250.

Bordwell, D. and Carroll, N. (eds.) (1996) Post-Theory. Reconstructing Film Studies. Madison: University of Wisconsin Press.

Burgin, V. (ed.) (1987) Thinking Photography. London: Macmillan.

Burgin, V. (1996) In/Different Spaces: Place and Memory in Visual Culture. Berkeley: University of California Press.

Burgin, V., Donald, J. and Kaplan, C. (eds.) (1986) Formations of Fantasy. London: Methuen.

Carrington, V. (2005) The uncanny, digital texts and literacy. Language and Education 19(6): 467-482.

Cohen, S. (2001) States of Denial. Knowing about Atrocities and Suffering. Cambridge: Polity Press.

Davis, T. and Womack, K. (2001) Formalist Criticism and Reader-Response Theory. London: Palgrave/Macmillan.

Deleuze, G. and Guattari, F. (1983) Anti-Oedipus. Capitalism and Schizophrenia, Translated by R. Hurley, M. Seem, and H.R. Lane. London: Athlone Press.

Douglas, M. (1988) Purity and Danger. An Analysis of the Concepts of Pollution and Taboo. London: ARK.

Freud, S. (1910, 1957) Leonardo Da Vinci and a memory of his childhood. Standard Edition 11. London: Hogarth Press, pp. 63-197.

Freud, S. (1914, 1955) The Moses of Michaelangelo. Standard Edition 13. London: Hogarth Press, pp. 211-238.

Freud, S. (1915, 1957) Repression. Standard Edition 17. London: Hogarth Press, pp. 146158.

Freud, S. (1919, 1955) The 'uncanny'. Standard Edition 17. London: Hogarth Press, pp. 217-256.

Frosh, P. (2001) The public eye and the citizen-voyeur: Photography as a performance of power. Social Semiotics 11(1): 43-59.

Fuller, P. (1983) Art and Psychoanalysis. London: Writers and Readers.

Heischman, D.R. (2002) The uncanniness of September 11th. Journal of Religion and Health 41(3): 197-205.

Helsingin Sanomat. (2007) Lost at sea. Photograph by Hannes Heikura, Helsingin Sanomat 14.8.2007, p. A5. http://www.suomenlehtikuvaajat.fi/vuodenlehtikuvat2008/ $2007 /$.

Hoile, C. (1984) The uncanny and the fairy tale in Kubrick's The Shining. Literature/Film Quarterly 12(1): 5-12.

Israeli, N. (2005) Reflections on Freud's 'the uncanny'. Existential Analysis 16(2): 378-389.

Jameson, F. (1981) The Political Unconscious: Narrative as a Socially Symbolic Act. London: Methuen.

Meinzer, K. (1996) Symmetries of Nature. A Handbook for Philosophy of Nature and Science. Berlin: Walter de Gruyter.

Royle, N. (2003) The Uncanny. New York: Routledge. 
Salvio, P.M. (2009) Uncanny exposures: A study of the wartime photojournalism of Lee Miller. Curriculum Inquiry 39(4): 521-536.

Seppänen, J. (2006) The Power of the Gaze. An Introduction to Visual Literacy. Translated by A. Ahonen and K. Clarke. New York: Peter Lang.

Solomon-Godeau, A. (1993) Photography at the Dock. Essays on Photographic History, Institutions and Practices. Minneapolis: University of Minnesota Press.

Weber, S. (1973) The sideshow, or: Remarks on a canny moment. MLN 88(6): 1102-1133. 